archives

of thermodynamics

Vol. 35(2014), No. 1, 87-98

DOI: 10.2478 /aoter-2014-0006

\title{
Experimental investigation of heat transfer performance coefficient in tube bundle of shell and tube heat exchanger in two-phase flow
}

\author{
MARCIN KARAŚ \\ DANIEL ZAJAC ${ }^{*}$ \\ ROMAN ULBRICH
}

Opole University of Technology, Department of Environmental Engineering, Prószkowska 76, 45-758 Opole, Poland

\begin{abstract}
This paper presents the results of studies in two phase gasliquid flow around tube bundle in the model of shell tube heat exchanger. Experimental investigations of heat transfer coefficient on the tubes surface were performed with the aid of electrochemical technique. Chilton-Colburn analogy between heat and mass transfer was used. Twelve nickel cathodes were mounted on the outside surface of one of the tubes. Measurement of limiting currents in the cathodic reduction of ferricyanide ions on nickel electrodes in aqueous solution of equimolar quantities of $\mathrm{K}_{3} \mathrm{Fe}(\mathrm{CN})_{6}$ and $\mathrm{K}_{4} \mathrm{Fe}(\mathrm{CN})_{6}$ in the presence of $\mathrm{NaOH}$ basic solution were applied to determine the mass transfer coefficient. Controlled diffusion from ions at the electrode was observed and limiting current plateau was measured. Measurements were performed with data acquisition equipment controlled by software created for this experiment. Mass transfer coefficient was calculated on the basis of the limiting current measurements. Results of mass transfer experiments (mass transfer coefficient) were recalculated to heat transfer coefficient. During the experiments, simultaneously conducted was the the investigation of two-phase flow structures around tubes with the use of digital particle image velocimetry. Average velocity fields around tubes were created with the use of a number of flow images and compared with the results of heat transfer coefficient calculations.
\end{abstract}

Keywords: Two-phase flow; Heat transfer coefficient; Tube bundle; Heat exchanger; DPIV

\footnotetext{
${ }^{*}$ Corresponding Author. E-mail: d.zajac@po.opole.pl
} 


\section{Nomenclature}

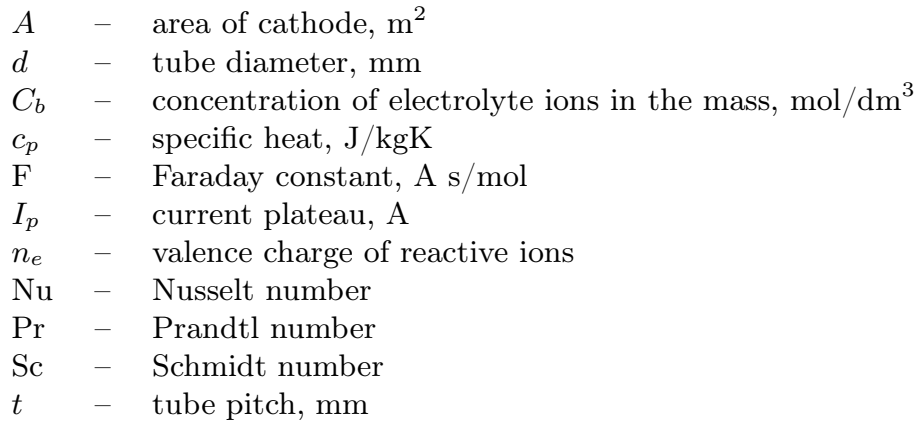

\section{Greek symbols}

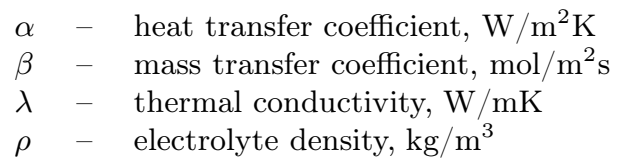

\section{Introduction}

The classic shell and tube heat exchangers are a commonly used flowthrough apparatus for heat exchange. External fluid is oriented transversely or longitudinally to the bundle of tubes embedded in the headers. In order to increase heat flux, in the flow area there are often introduced transverse baffles.

Two-phase mixture flow in the space between tube bundle is characterized by high fluctuations that result from the oscillatory nature of the twophase flow and the complex geometrical shape of the tube bundle. Due to the fact that construction of the tube bundle in the heat exchanger model is characterized by the same geometric parameters (array of tubes, tube pitch, tube diameter) as the actual heat exchangers, it is possible to study of two-phase fluid movement and transfer the results to the real devices.

Two-phase flow in the tube bundle is characterized by considerable irregularity of flow around tubes and the occurrence of the flow of heterogeneous areas. The effect of nonuniformity of two-phase flow becomes an important parameter describing the flow of a mixture of gas-liquid in the tube bundle, and its identification is important for the design and operation of heat exchangers. In the literature, experimental studies have been conducted in the models of heat exchangers inside tube bundle, in the area where the flow is stabilized (in the middle rows of tube bundles), although in the actual 
shell and tube heat exchangers, cross flow through tubes may have place only for a few rows of tubes (between adjacent edges of the baffles there are often only a few rows of tubes). Therefore, it is important to study the flow in the space between, especially in the first rows, in which occurs an evolution of the two-phase flow.

Hydrodynamic structures formed during the flow of gas-liquid mixture in the heat exchanger significantly affect the parameters of the device. Their influence may determine not only the intensity of heat exchange, but also can be linked with the problems of vibration in the tube bundle of the heat exchanger. Therefore, identification and analysis of two-phase flow structures can be regarded as an important element that describes the phenomena occurring in the tube bundle of the heat exchanger. Identification and classification of hydrodynamic structures is carried out generally in the way of visual experiments, so not only dynamic parameters of the flow could be determined but also the shape and evolution of flow structures [10].

Predicting conditions for the heat exchangers as devices used in various systems and configurations (from the steam boilers to micro heat exchangers for electronic components) is very difficult. There are many different phenomena of fluid flow and heat transfer in heat exchangers that can be solved individually, but in the whole dimension of complexity are difficult or impossible to calculate. That is, for a number of difficulties in the mathematical description of these issues. These problems stem from the complexity of the geometry of flow systems, turbulent flow, the difficulty in defining the boundary conditions, a strong variation of the coefficients of heat transfer, nonuniform fluid temperature and the different parameters of various liquids $[4,5]$. So often, in order to gain detailed knowledge about the propagation of heat in the volume of heat exchange apparatus, there are used to approximate experimental methods for determining the heat transfer coefficient (based on the analogy between the processes of heat and mass transfer), used also because of lower cost than the thermal measurements led directly to the real object. One of the most common experimental methods for determining the coefficient of heat transfer in forced convection conditions is the electrochemical method.

Among the many techniques to measure and visualize the flow structures, digital imaging velocimetry is most often used to study the flow around the tube bundle. In the past few years conducted research on the flow of two and one phase digital particle image velocimetry (DPIV) using high-speed cameras. Most of the authors are using this technique to 
describe single-phase flows, however, in the literature can be found results which use DPIV technique for two-phase flow analysis $[2,6,7]$.

One of the many factors influencing the efficiency of heat exchange equipment is the convective heat transfer coefficient. This coefficient is usually determined experimentally because of the difficulty of deriving in an analytical way. One way to obtain it is to apply a method based on the analogy of heat and mass transfer using the electrolysis technique. In literature, few papers can be found using this method to analyze heat exchangers. In [11] electrolysis technique was used to study the transport of mass and heat transfer in minichannels, while in [9] investigated the nonunifornity of heat exchange in heat exchanger tube bundle of conventional dimensions.

The aim of this research is to estimate the effect of flow parameters on the conditions of heat exchange through simultaneous measurements using electrochemical methods (determination of mass transfer coefficient and further by Chilton-Colburn analogy heat transfer coefficient) and DPIV (determination of velocity fields). Unlike the research methodology presented in the literature, simultaneous measurement of both characteristics allows for a more accurate interpretation of the heat-flow dependencies relationship.

\section{Experimental set-up}

Scheme of the measurement set-up is shown in Fig. 1 The study involved two sets of tube bundle configurations made of plexiglass - staggered and in-line. At the bottom of the exchanger was placed the mixing chamber of the two phases. Diameter of the tubes $d$ was $15 \mathrm{~mm}$ and pitch $t 20 \mathrm{~mm}$ so $t / d$ was equal to 1.33 . Nitrogen flow rate was set by rotameter. The liquid was pumped in a closed loop by a centrifugal pump with magnetic coupling, before entering the heat exchanger fluid flow measured by rotameter. In the absence of the pump speed control, adjustable liquid flow took place through the circulation valve (bypass). Phase separation occurred after leaving the heat exchanger by the two phase mixture flow into the tank.

Flow field was illuminated by a continuous green laser with the power of $1 \mathrm{~W}$, producing a light beam of wavelength $\lambda=532 \mathrm{~nm}$. Illuminated flow field was recorded by the CMOS camera (HCC-1000 Voeskuhler) [11] at a resolution of $1024 \times 1024$ pixels. Flow images were recorded directly as a bitmap at a frequency of $462 \mathrm{~Hz}$.

To measure the current nickel electrode system was used, shown in Fig. 2. 


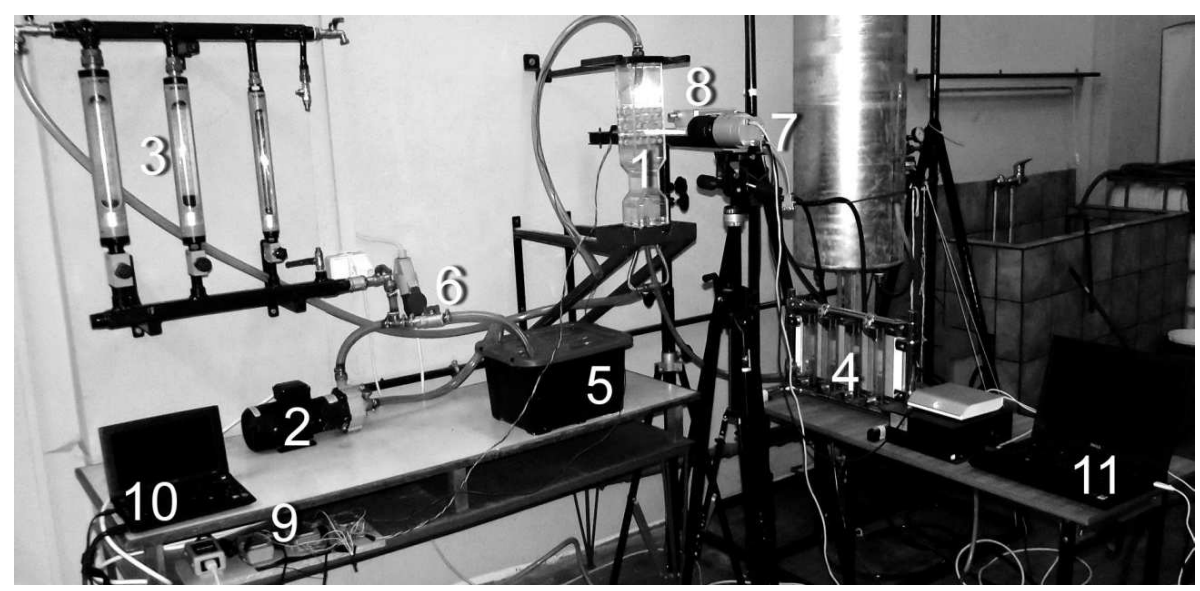

Figure 1. Experimental set-up: 1 - tube bundle, 2 - pump, 3,4 - rotameters, 5 - electrolyte tank, 6 - bypass, 7 - camera, 8 - laser, 9 - recording modules, 10,11 data collection.

Electrodes immersed in an aqueous solution of potassium in the form of nickel anode grid were located at the outlet of the electrolyte from the heat exchanger. The cathode was used as a nickel-plated brass plaque on the circumference of the tube. The applied electrical system permits the delivery of a specific, stepwise increasing and stabilized voltage direct current flowing through the electrolyte solution between the cathode and the anode.
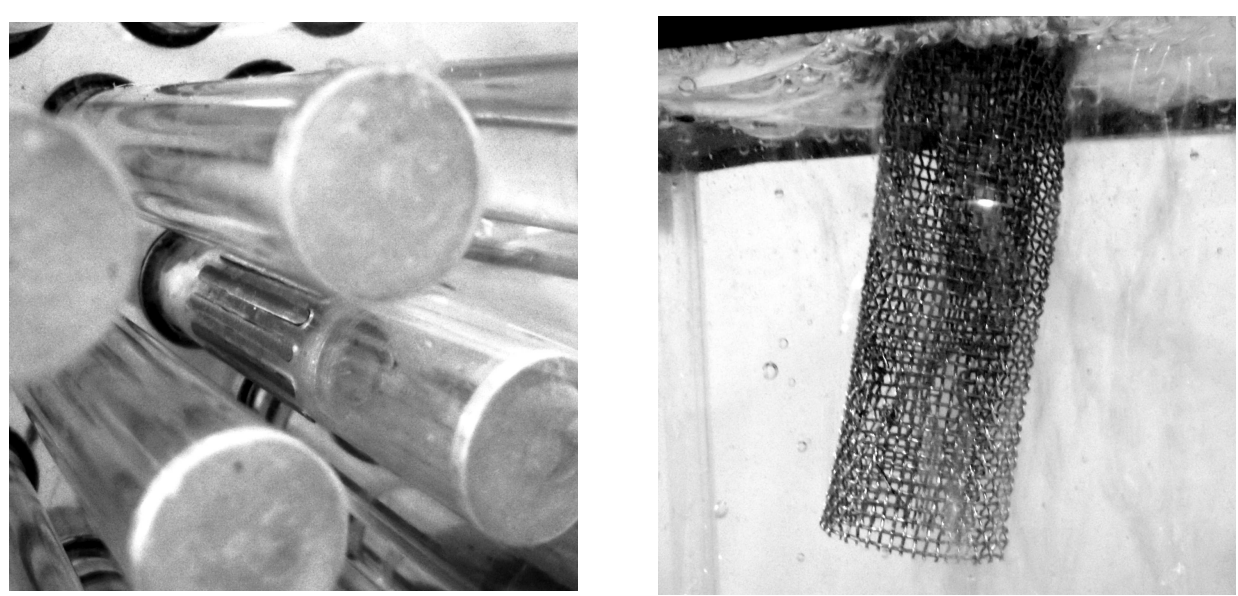

Figure 2. Nickel electrodes. 
System uses three analog modules. The task of the first of them was applying to the system current with established and growing voltage, the other two modules were responsible for reading the current values of each of the plaques from the perimeter of the tube. In order to properly control all the modules of applied software was written using the LabVIEW programming environment [8]. This enabled the determination of values such as minimum and maximum voltage and its increment. All data were archived immediately after the measurement as a text file. Control and archiving was conducted using a regular PC.

\section{Measurements}

The measurements were performed for three different flow rates of gas and liquid; the liquid phase was set respectively 200,400 and $600 \mathrm{dm}^{3} / \mathrm{h}$, and gas on 5,10 and $20 \mathrm{dm}^{3} / \mathrm{h}$. Measurement series were performed for the staggered and in-line setup. Images were recorded with macro lens to obtain the velocity field around the individual tubes.

Table 1. Indications and value of the flow rates for a series of measurements carried out.

\begin{tabular}{|c|c|c|c|c|c|c|c|}
\hline \multicolumn{4}{|c|}{ In line tube bundle } & \multicolumn{4}{|c|}{ Staggered tube bundle } \\
\hline \multirow{2}{*}{ No. } & Symbol & Liquid & Gas & \multirow{2}{*}{ No. } & Symbol & Liquid & Gas \\
\hline & & $\mathrm{dm}^{3} / \mathrm{h}$ & $\mathrm{dm}^{3} / \mathrm{h}$ & & & $\mathrm{dm}^{3} / \mathrm{h}$ & $\mathrm{dm}^{3} / \mathrm{h}$ \\
\hline 1 & L200G05L & 200 & 05 & 1 & L200G05S & 200 & 05 \\
\hline 2 & L200G10L & 200 & 10 & 2 & L200G10S & 200 & 10 \\
\hline 3 & L200G20L & 200 & 20 & 3 & L200G20S & 200 & 20 \\
\hline 4 & L400G05L & 400 & 05 & 4 & L400G05S & 400 & 05 \\
\hline 5 & L400G10L & 400 & 10 & 5 & L400G10S & 400 & 10 \\
\hline 6 & L400G20L & 400 & 20 & 6 & L400G20S & 400 & 20 \\
\hline 7 & L600G05L & 600 & 05 & 7 & L600G05S & 600 & 05 \\
\hline 8 & L600G10L & 600 & 10 & 8 & L600G10S & 600 & 10 \\
\hline 9 & L600G20L & 600 & 20 & 9 & L600G20S & 600 & 20 \\
\hline
\end{tabular}

Electrochemical measurements are based on recording the intensity of the electrical voltage changes during the controlled diffusion of ions at the electrode. For the measurements used electrodes immersed in a solution of an equimolar mixture of $\mathrm{K}_{3} \mathrm{FE}(\mathrm{CN})_{6}$ and $\mathrm{K}_{4} \mathrm{Fe}(\mathrm{CN})_{6}$, in the presence of 
sodium hydroxide as a base electrolyte. To achieve controlled diffusion at the cathode it has to be ensured that anode surface is significantly bigger than the cathode [1]. Schema of the oxidation-reduction process at the electrodes, with the use of power supply (AC), is shown in Fig. 3.

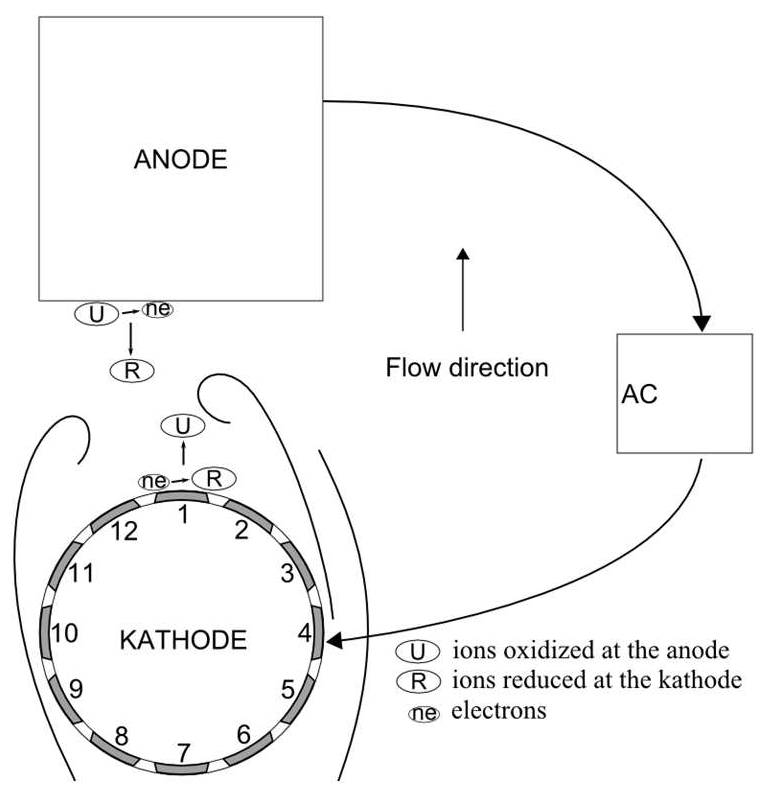

Figure 3. Scheme of the oxidation-reduction process at the electrodes.

After connecting the constant, stabilized voltage, the electrical circuit is formed between the electrodes. Initially, current increases with increasing voltage until the incident at which the diffusion-controlled electron transfer occurs on the surface of the electrodes under constant current value. This value is called the intensity of current plateau. Example of a limiting plateau current plot is shown in Fig. 4. The plateau current value is used to calculate the mass transfer coefficient, according to the formula

$$
\beta=\frac{I_{p}}{n_{e} F A C_{b}} .
$$

Having determined the mass transfer coefficient of heat $\beta$ then applied Chilton-Colburn analogy [3] between heat and mass transfer. This allowed for the calculation of heat transfer coefficient $\alpha$ on the surfaces of the tubes.

$$
\alpha=\beta \rho c_{p}\left(\frac{\mathrm{Sc}}{\mathrm{Pr}}\right)^{\frac{2}{3}},
$$




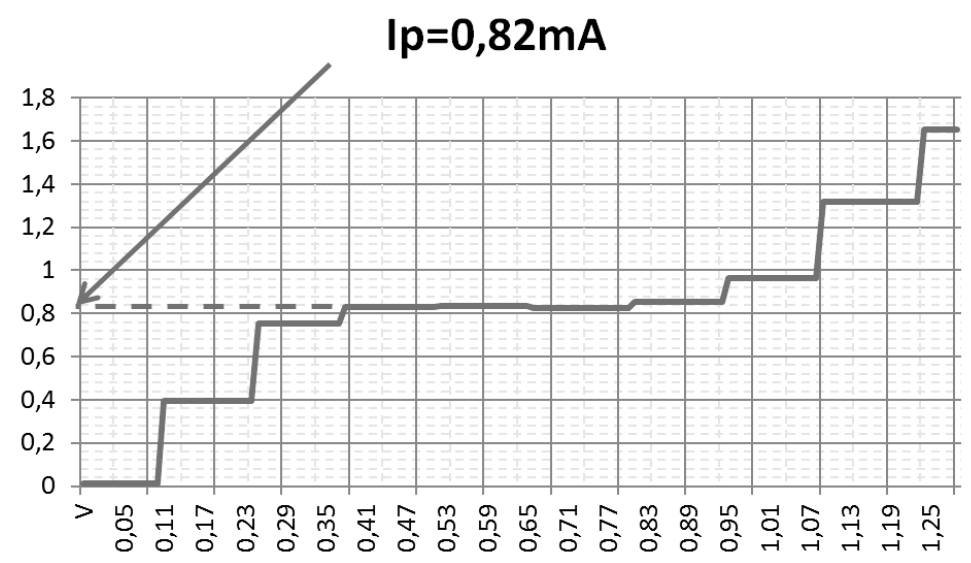

Figure 4. Example of limiting plateau current.

Knowing the value of heat transfer coefficient could then be calculated Nusselt number

$$
\mathrm{Nu}=\frac{\alpha d}{\lambda} .
$$

Fluid velocity field around the test tubes were calculated using DPIV. It is a method involving the recordings of the tracers introduced into liquid phase. Comparison of two successive images and determine their correlation coefficient allows the creation of instantaneous velocity vector fields.

Images as bitmap images obtained directly from the recording shown in Fig. 5 were analysed using Matlab prepared software [12]. This analysis was based on the determination of the displacement vector of the flow tracers in several successive images using cross-correlation function. The results of the analysis were the vector velocity field. Measurements of voltage to the electrochemical method were performed simultaneously with the recording of images used in the calculation method of particle image velocimetry.

\section{Results}

Velocity fields around a single tube show in the same way the flow of liquid on the sides of the tube. There were no major changes in speed when changing the flow rates of the phases. The maximum speed recorded was $22 \mathrm{~mm} / \mathrm{s}$. Shown are the local fluid velocity increases due to the flowing air bubbles. In such places, the movement speed of tracers was too high 

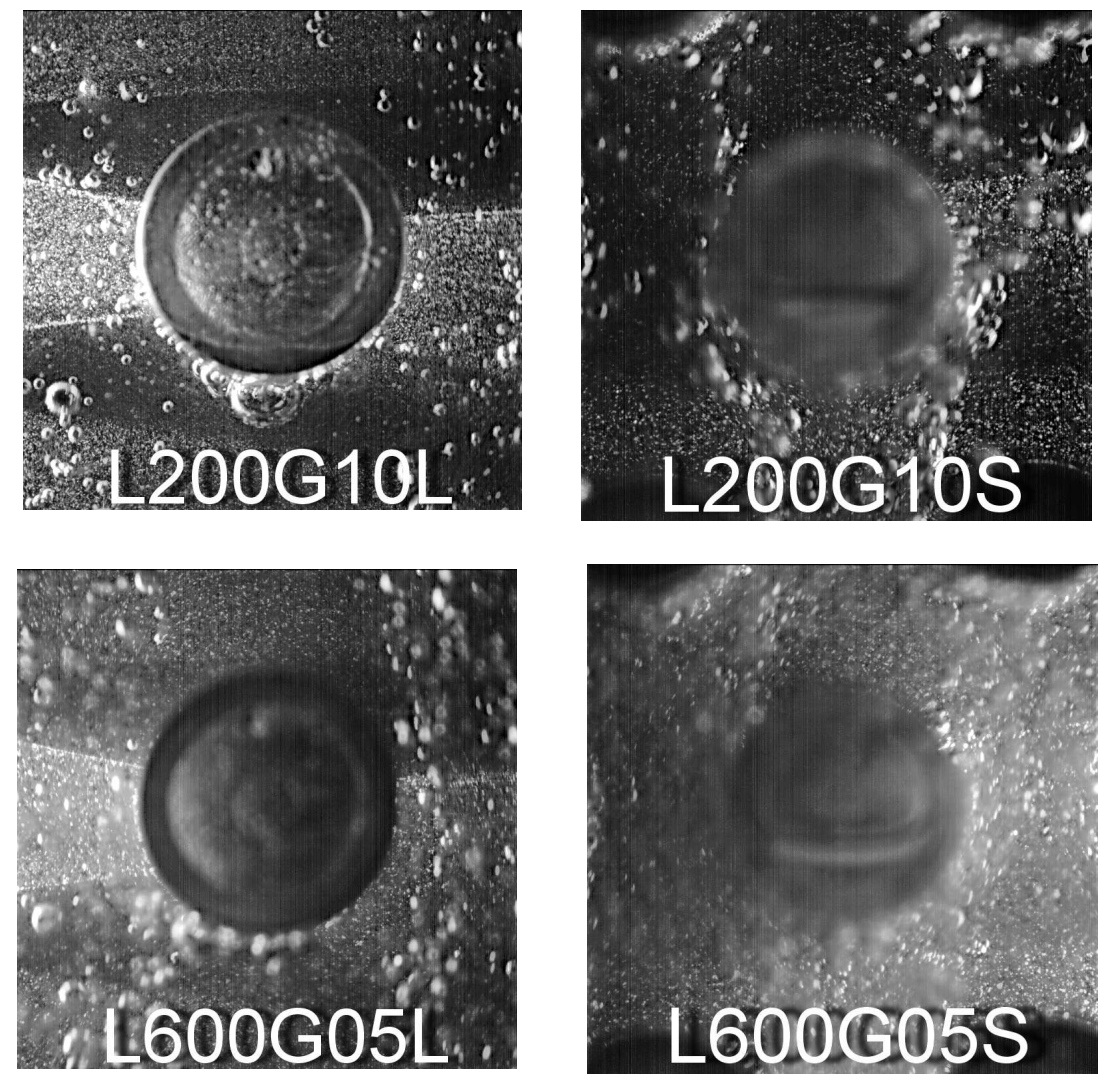

Figure 5. Exemplary images of the flow.

to determine the velocity field. The flow of the tested mixture of phases for both in-line and staggered tube bundle was characterized by a high velocity flow areas on the sides of the tubes, and in front of the tubes. In the zones located behind tubes were observed smaller velocities, flow stagnation zones or falling direction of flow. There was also some number of vortex structures. A larger number of such structures were observed for the staggered tube bundle. Also for this system, the place of occurrence was less regular.

The results of the electrochemical method are presented in graphs of the local Nusselt numbers, which are equivalent to the dimensionless heat transfer coefficient. The highest values for most studied cases were observed in the frontal part of the tubes or in a place where there was the greatest velocity, and thus the thickness of the laminar layer is the lowest. In the back 

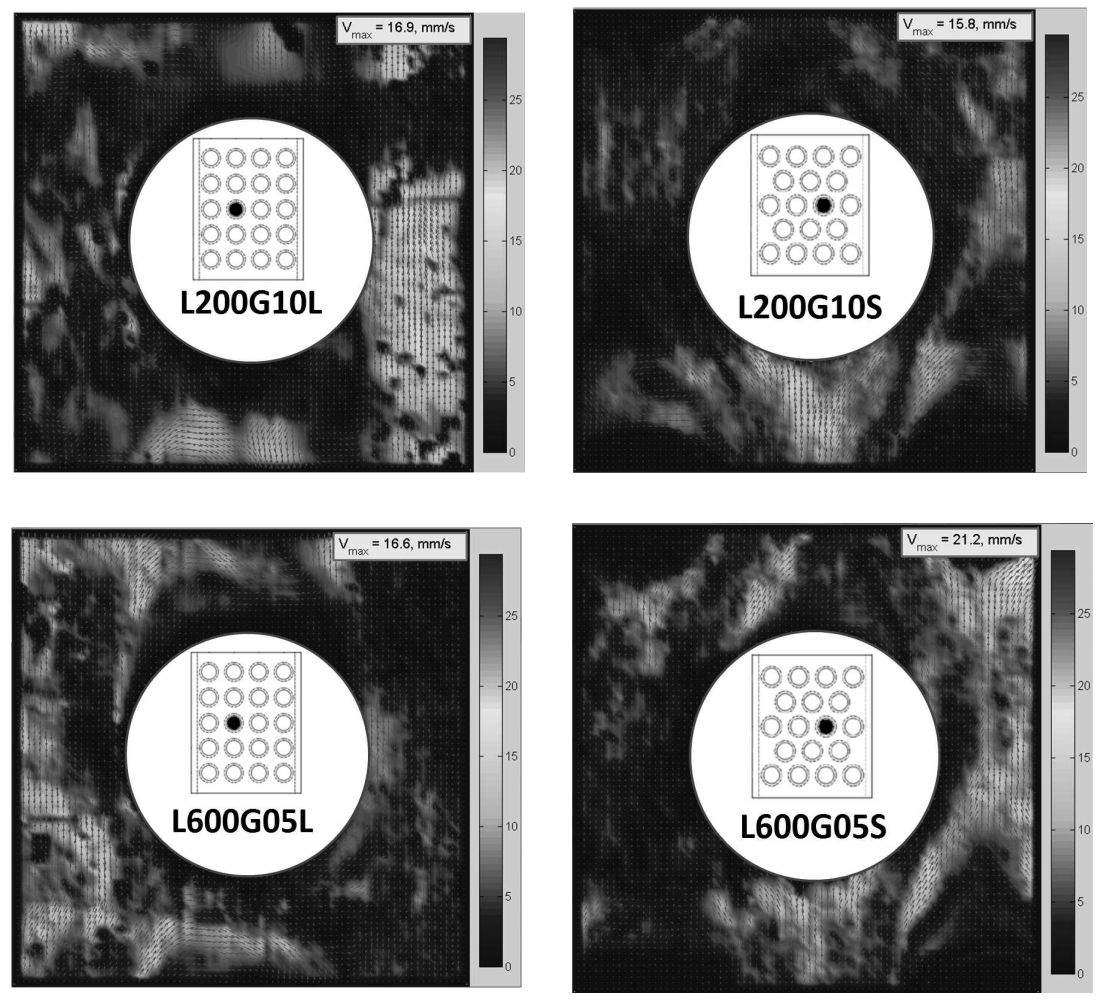

Figure 6. Example of obtained flow fields for staggered and in-line tube arrangement.

of the tubes Nusselt number value is much smaller. Comparing staggered vs. in-line tube bundle results there is a clear area located in the front of the tubes, where for the in-line arrangement the $\mathrm{Nu}$ values were lower than on the sides. There are two distinct peaks in the vicinity of $120^{\circ}$ and $240^{\circ}$. This is due to a lower velocity of liquid phase caused by the preceding tube.

\section{Conclusions}

Staggered arrangement was characterized by a greater uniformity of heat transfer coefficient. Also for this arrangement there was no minimum values of heat transfer coefficient on the frontal area of the tubes - so characteristic for the in-line tube bundles. For both arrangements higher Nusselt number was observed fort the frontal tubes area on the side which was the 

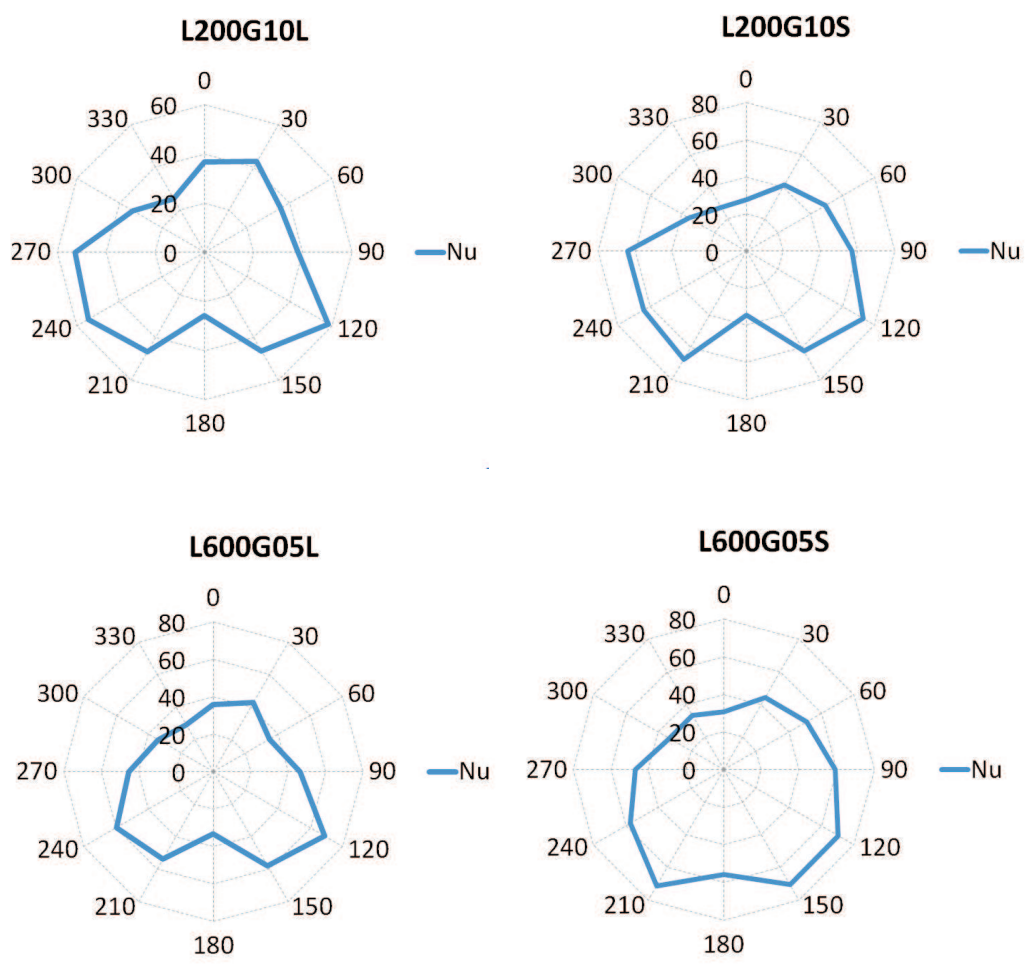

Figure 7. Distribution of Nusselt number around tubes.

closest to the tube bundle model axis.

The distribution of polarization curves changes with the fluid flow rate. It can be concluded that a significant impact on the nonuniform distribution of heat transfer coefficient on the surface of the tubes has a stochastic nature of the two-phase flows. The flow of bubbles has a significant impact on the flow velocity of the liquid phase, which influences the intensity of heat and mass transfer.

Chaotic way of the two-phase flow mixture flow behind the tubes was observed. In these places occurred creating, merging and disappearance of vortices, the motion of the mixture in all directions, stagnation of the flow velocity or changes in local streams at the invariant phases brought into the test loop. Stagnation zones change their volume and position during the measurements at fixed values of streams of the phases.

Based on the results obtained with DPIV method (velocity fields and streamlines) it can be visible that there is a considerable irregularity two- 
phase flow hydrodynamics of gas-liquid in flow field over tube bundle.

Acknowledgements This research was supported by Polish Ministry of Science and Higher Education research grant 4790/B/T02/2010/3.

Received 15 September 2012

\section{References}

[1] Bieniasz B.: Convective mass/heat transfer for the sheet rotors of the rotary regenerator. Publishing house of Rzeszów University of Technology, Rzeszów 2005 (in Polish).

[2] Burnside B.M., Miller K.M., McNeil D.A., Bruce T.: Flow velocities in an experimental kettle reboiler determined by particle image velocimetry. Int. J. Heat Mass Transfer 48(2004), 1000-1016.

[3] Chilton T.H., Colburn A.P.: Mass transfer (absorption) coefficients prediction from data on the heat transfer and fluid friction. Ind. Eng. Chem. 26(1934), 11831187.

[4] Grant I.D.R., Murray I.: Pressure drop on the shell-side of a segmentally baffeled shell-and-tube with horizontal two phase flow. NEL Report 560(1974).

[5] Grant I.D.R., Murray I.: Pressure drop on the shell-side of a segmentally baffeled shell-and-tube with vertical two phase flow. NEL Report 500(1972).

[6] Imaki C., Cheong K.H., Monji H., Matsui G.: PIV measurement of the vertical cross-flow structure over tube bundles. Exp. Fluids 37(2004), 350-363.

[7] Imaki C., Cheong K.H., Monji H., Matsui G.: Vertical, bubbly, cross-flow characteristics over tube bundles. Exp. Fluids, 39(2005), 1024-1039.

[8] Karaś M., Zając D., Ulbrich R.: Simultaneous two-phase flow structures characteristics and heat exchange coefficient examination over tube bundle. Proc. 14th Int. Symp. Heat Transfer and Renewable Sources of Energy, Szczecin-Międzyzdroje 2012, 349-380.

[9] SiEjKA K.: Irregularity of heat exchange with two phase flow around tube bundle. PhD thesis, Opole UT, Opole 2006 (in Polish).

[10] Ulbrich R., Mewes D.: Vertical, upward gas-liquid two-phase flow across a tube bundle. Int. J. Multiphase Flow (1994), 279-294.

[11] Wilk J.: Experimental investigation of convective mass/heat transfer in short minichannel at low Reynolds numbers. Exp. Ther. Fluid Sci. 33(2009), 267-272.

[12] ZająC D., Ulbrich R.: Non invasive experimental methods of two phase gas-liquid flow analysis. Publ. House of Opole UT, Studies and Monographies - Opole UT, Vol. 174, Opole 2005, ISSN 1429-6063 (in Polish). 